\title{
Action Sport Media Consumption Trends Across Generations: Exploring the Olympic Audience and the Impact of Action Sports Inclusion
}

Communication \& Sport

$|-3|$

(C) The Author(s) 2018

Reprints and permission: sagepub.com/journalsPermissions.nav DOI: $10.1177 / 2167479518780410$ journals.sagepub.com/home/com

SAGE

\section{Belinda Wheaton' and Holly Thorpe'}

\begin{abstract}
The ageing demographics of Olympic viewers is a key concern for the International Olympic Committee. The inclusion of action sports into the Olympic programmes has been a key strategy to try and connect with youth consumers, most recently through the inclusion of skateboarding, surfing, and sport climbing into the Tokyo 2020 summer games. Drawing on a questionnaire distributed online in nine languages, and contextualized with analysis of the action sport media, our research explores international and multigenerational action sport consumers' sport viewing preferences and attitudes to the Olympic inclusion of action sports. Our findings suggest that action sport participants across different countries, ages, and genders are avid consumers of action sport media but also keen consumers of the Olympics. The majority of survey participants were enthusiastic about the inclusion of action sports (and particularly skateboarding) into the Olympic Games, although there were important trends across nationalities and ages. Nonetheless, reflecting debates in the subcultural media, participants also have concerns about the processes and

\footnotetext{
' Te Huataki Waiora Faculty of Health, Sport and Human Performance, The University of Waikato-Te Whare Wānanga o Waikato, Hamilton, New Zealand

Corresponding Author:

Belinda Wheaton, Te Huataki Waiora Faculty of Health, Sport and Human Performance, The University of Waikato-Te Whare Wānanga o Waikato, Private Bag 3105, Hamilton 3240, New Zealand.

Email: bwheaton@waikato.ac.nz
} 
politics of action sports inclusion. Action sports may well provide the International Olympic Committee with new lucrative markets, but to maximise the engagement of complex intergenerational audiences, their viewing preferences will need continued attention and understanding.

\section{Keywords}

action sport, Olympics, Tokyo 2020, youth, skateboarding, Generation Y

The Olympics is the most watched sporting spectacle in the world (Billings, 2008; Sugden \& Tomlinson, 2011; Wenner \& Billings, 2017). Yet the relevance of the Olympics in the contemporary mediascape has been questioned, particularly for younger viewers whose sport consumption patterns differ from previous generations (Billings, 2011; Lines, 2000; Rowe \& Gilmour, 2010; Thorpe \& Wheaton, 2017; Wenner, 2010; Wenner \& Billings, 2017). With an expanding range of leisure activities, including the Internet, music, and video games, television (TV)-based sports are increasingly competing for the attention of young people, particularly teenage boys. Such changes have led to diminishing numbers of young Olympic viewers (Chang, 2016), along with youth consumption of previously popular national team sports such as basketball and baseball in the United States (Kellett \& Russell, 2009; Ourand \& Karp, 2012).

The ageing demographics of Olympic viewers are a key concern for the Olympic movement (Thorpe \& Wheaton, 2011a, 2011b). The median age of U.S. viewers for the 2008 Beijing Olympics was 47, rising to 48 for the 2012 London Games, and 53 for the 2016 Rio Games (Chang, 2016; Lombardo \& Broughton, 2017). Between London and Rio, there was a 30\% drop in TV viewers between the ages of 18 and 34 (Flint \& Vranica, 2016). The International Olympic Committee (IOC) has implemented and is implementing a range of measures to appeal to younger viewers such as introducing the Youth Olympics Games (YOG) and the Olympic Internet TV channel (2016). Another key strategy has been introducing youth-focused action sports into both the summer (e.g., windsurfing, mountain biking, bicycle motocross) and winter (e.g., snowboarding, skier cross) programs (Bialik, 2002; Thorpe \& Wheaton, 2011b). The action sport "genre" was a consistently growing section of the sports industry through the 1990s and 2000s and has been widely linked with the "elusive Generation Y market" (G. Bennett \& Lachowetz, 2004, p. 239; Kellett \& Russell, 2009; Walker, Soroka, \& Kellett, 2005). The IOC has been strategic in trying to respond to these trends, but their efforts have not been without controversy (Thorpe \& Wheaton, 2011a, 2011b).

From the perspective of the IOC and media corporations, snowboarding has been a particularly successful addition to the Olympic programme (Dillman, 2010). For example, $32 \%$ of the U.S. population (92 million people) watched the 2002 Salt Lake City Olympic snowboarding half-pipe competition in which Americans won gold, 
silver, and bronze in the men's event and gold in the women's event, contributing to a $23 \%$ increase in ratings among 18 - to 34-year-old viewers (see Thorpe \& Wheaton, 2011 b, p. 188). Snowboarding has also been credited for the $48 \%$ increase in 18 - to 24-year-old viewers at the 2010 Vancouver Winter Olympics (Bauder, 2010). In the United States, coverage of Shaun White winning his third gold medal in Men's HalfPipe at the 2018 Pyeongchang Winter Olympic Games attracted a record 22.6 million viewers on National Broadcasting Company (NBC) and NBC Sports Network alone (de Moraes, 2018). In 2016, the IOC attempted to do something similar at the Summer Olympic Games by announcing that surfing, skateboarding, and sport climbing will be included in the Tokyo 2020 Summer Games, as part of IOC President Thomas Bach's Agenda 2020 reforms for the Olympic movement. "We want to take sport to the youth" said Bach, "with the many options that young people have, we cannot expect any more that they will come automatically to us - we have to go to them" (cited in Jones, 2016).

In this article, we explore this latest and most substantial attempt to use action sports to entice youth consumers to the Summer Olympic Games. In so doing, we contribute to understandings of the media consumption of action sport genre and its relationship with contemporary "youth" consumers. Writing over 15 years ago, G.Bennet, Henson, and Zhang (2003) argued, "given the current media hype surrounding action sports and its popularity amongst members of Gen Y, this particular genre of sports appears to be an especially fertile topic for future investigation" (p. 112). Yet despite the continued growth of the action sport market both in the United States and internationally, such calls have gone largely unanswered, and there remains a dearth of research exploring the media preferences of action sport consumers (G.Bennett, Sagas, \& Dees, 2006). Furthermore, a limitation of existing research is the North American focus and rather narrow age-based conceptualisation of the action sport market as youth. Our research seeks to provide a more intergenerational and international focus.

\section{Action Sports and the Youth Market}

Since the late 1990s, a growing body of literature has examined the rise of action sports around the world (e.g., Rinehart \& Sydor, 2003; Thorpe, 2014; Thorpe \& Olive, 2016; Wheaton, 2012, 2013). Sociologists of sport and media have examined the media consumption and production patterns within various action sports cultures (e.g., Beal \& Smith, 2010; Booth, 2008; Gilchrist \& Wheaton, 2013; Ormrod, 2009; Rinehart, 2008; Thorpe, 2017; Thorpe \& Wheaton, 2017; Wheaton \& Beal, 2003), with fewer exploring trends across sports or countries. Both in popular cultural media and some strands of academic literature, participation in and consumption of the action sport genre, both in the United States (G.Bennett \& Lachowetz, 2004, p. 239; G.Bennett et al., 2006) and more globally (Kellett \& Russell, 2009; Salome \& van Bottenburg, 2012; Walker et al., 2005), have been associated with Generation Y (Gen Y) lifestyles. Gen Y, also called the millenniums, is a term deriving from 
marketing which in the United States has been used to describe the lucrative and sizeable contemporary youth market that followed after Generation X (Gen X) and the Baby Boomers. While Gen Y's exact characterization varies between commentators, ${ }^{1}$ many sources describe it as those born between 1977 and 1994, so aged 24-36 in 2018 (G.Bennett, Henson, \& Zhang, 2003). More recently, a new youth segment-Gen Z- has been used to refer to those born between 1995 and 2012 (currently aged 5-22; Beall, 2016).

These youth markets are considered important due to their size and influence. Gen Y is described as a large and lucrative population (G.Bennett \& Lachowetz, 2004, p. 239), 3 times the size of its predecessor, Gen X (G.Bennett et al., 2003). Generation Z (Gen Z) already makes up $25.9 \%$ of the U.S. population, and it is estimated that by 2020, they will account for one third of the U.S. population (Beall, 2016). Furthermore, the sport and media consumption patterns of Gen Y were seen to differ from previous generations, and they are characterised as being very media savvy (G.Bennett et al., 2006). Gen $\mathrm{Z}$ and $\mathrm{Y}$ are considered by sports marketers as highly desirable targets for corporations, but as G. Bennett and Lachowetz (2004) discuss, they are also "difficult to reach and to influence" (p. 239).

According to Giannoulakis and Krol Pursglove (2017), members of Gen Y consume action sports (as athletes and lifestyle participants) more than any preceding generation, leading some to labelling action sports as "Gen-Y sports" (p. 141). As G.Bennett and Lachowetz (2004) outline, the growth of major action sports events from the late 1990s such as the Gravity Games and the X Games can be seen as attempts by broadcasters, marketers, and advertisers to actively commercialise action sports into a package to reach the Gen Y market (Rinehart, 1998; Thorpe, 2014). Although the action sport industry was initially characterised as countercultural and niche, it too has become increasingly profit-driven with entrepreneurial individuals creating opportunities to sustain their lifestyles and make profit (Beal \& Weidman, 2003; Kusz, 2004; Rinehart, 2008; Rinehart \& Sydor, 2003; Thorpe \& Dumont, 2018).

It is not surprising then that the IOC continues to draw inspiration from successful action sport media events, such as the $\mathrm{X}$ Games, in their attempts to engage and inspire younger viewers (Thorpe \& Wheaton, 2011b, 2017). The representational styles developed by the X Games with their fusion of Gen Y-style activities - action sports, music, and computer gaming - are increasingly evident in Olympic action sport events and programming (Thorpe \& Wheaton, 2017). However, the IOC's most substantial attempt yet to connect to the Gen $\mathrm{Y}$ and Gen $\mathrm{X}$ audience through action sports is the forthcoming inclusion of surfing, skateboarding, and sport climbing into the Tokyo 2020 Summer Olympics. The inclusion of these sports (along with baseball/softball and karate) came about as a result of the Agenda 2020 reforms aimed at making the Olympics more relevant and youth-focused and allowing host cities to apply for new sports to be added to their Olympic program (Thorpe and Wheaton, in press). With the IOC putting pressure on existing sports federations to ensure their events are attracting audiences, appealing to youth, and are gender 
equitable (Butler, 2017), the International Cycling Federation opted to include BMX freestyle (with quotas taken from other cycling events), with discussions about kitesurfing (under yachting) and parkour (under gymnastics) ongoing and hotly contested by core cultural members.

\section{Olympic Inclusion: Lessons From the Past}

Although the marriage between Gen Y and action sport has been good for corporations, the history of past action sports inclusion into the Olympics has illustrated that the process has not been a smooth one.

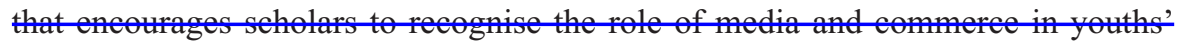
ellmal formations and acklodge form of aseney and polities within (andafter) prosses of institutionalisation and momolification has taken place (A. Bennett,

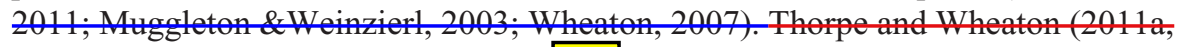
$2011 \mathrm{~b}$ ) have outlined the different prer ; and politics of incorperation for each aetionspert. In so doing, they reveal activn sports inclusion into the Olympic Games as a highly political and contested process, reflecting trends observed in other contemporary "postsubcultural" youth and sport cultures (Beal \& Wilson, 2004; Edwards \& Corte, 2010; Rinehart, 2008).

Within each action sport, there have been factions arguing for and against inclusion, with changes in attitude over time (Thorpe \& Wheaton, 2011a, 2011b). Early practitioners have been particularly wary of incorporation into these forms of competition organised by traditional sports organisations, seeing it as a form of "selling out" their "alternative" values and ideologies (Humphreys, 2003). While younger contemporary generations of action sport athletes seem more willing to embrace such opportunities, events such as the X Games and athlete-organized competitions continue to hold more cultural authenticity than the Olympics (Beal \& Wilson, 2004; Wheaton, 2005) and thus tend to be valued more highly within the sports cultures and industries (Thorpe \& Wheaton, 2011a).

Perhaps the most notorious public display of these early views came when World snowboard Champion Terje Haakonsen declined to participate in the 1998 Winter Olympics as a form of protest. In his own words, he was strongly opposed to snowboarders being turned into "uniform-wearing, flag-bearing, walking logo[s]" (Mellgren, 1998, para. 8). Yet, snowboarding has subsequently been amongst the most popular sports among viewers and audiences of the Winter Olympics, and many contemporary snowboarders now embrace the competition as an opportunity to perform on a global stage and reap the financial rewards. However, Haaksonsen (2004) continues in his critique of the Olympic Games and has organised the longstanding Arctic Challenge - an event run by and for snowboarders - as the antithesis to the Olympics (Bridges, 2014).

While the inclusion of snowboarding into the 1998 Winter Olympic Games has caused most debate and academic attention (Popovic \& Morrow, 2008; Thorpe, 2011; Thorpe \& Wheaton, 2011a), similar cultural contestation over incorporation 
has occurred in other action sports, such as windsurfing (Los Angeles, 1984), BMX (in 2008), and, more recently, kitesurfing and skateboarding (Honea, 2013; Thorpe \& Wheaton, 2011b). For example, when it was proposed that "Skateboarding could make its Olympic debut at the 2012 London Games" (Peck, 2007) under the sport of cycling, thousands of skateboarders from across the world responded by signing an online petition titled "No Skateboarding in the Olympics" addressed to the IOC president (The Petition, No Skateboarding in the Olympics! 2010). Similarly, following the announcement of the proposal to include skateboarding, surfing, and sport climbing in Tokyo 2020, a spate of articles appeared in both mainstream and niche media, many of which were concerned about their sports being sold-out. For example:

If it was in the Olympics, it wouldn't be skateboarding anymore. It'd be gymnastics on wood with wheels. It'd be overladen with rules and regs created by people who didn't know WTF they were talking about. (Comment posted on Vice magazine)

As Thorpe and Wheaton (2011a, 2011b) have illustrated, in each case of the Olympic incorporation of an action sport to date, market-driven processes have led to complex, contextually specific power struggles between international and national sporting governing bodies, media conglomerates, and action sports cultures and their industries. However, action sport cultures are multilayered, mobile, and ever-changing, incorporating a range of consumers and participants from elite athletes to hard-core aficionados to "weekend warriors" (Wheaton, 2013). Therefore, research needs to be attentive to these different consumers of action sport cultures (see Figure 1), and how different generations of participants and viewers regard this relationship between their sporting cultures and the Olympic Games.

\section{Beyond Youth? Gen X, Y, and Z}

Action sports research has grown over the past three decades, with researchers across an array of disciplines focused on different sports in local, national, and global contexts (see Thorpe \& Wheaton, 2014). However, much of this literature has focused on youth and in the context of North America. In examining the history and development of action sports, scholars have acknowledged the powerful role of the American action sports industry and media in defining global youth participation and consumption trends (Thorpe, 2014). This research builds upon and extends existing literature by providing a more intergenerational and international focus by exploring the media consumption practices of action sport participants across different age-groups and national contexts. Recent sociological literature has suggested that age demographics in action sports are broadening, thus challenging previous understandings of these sporting cultures as "youth cultures" as well as dominant media representations that have long focused on young (mostly male) highly athletic participants (Wheaton, 2017). Bennet et al. (2006) compared the 


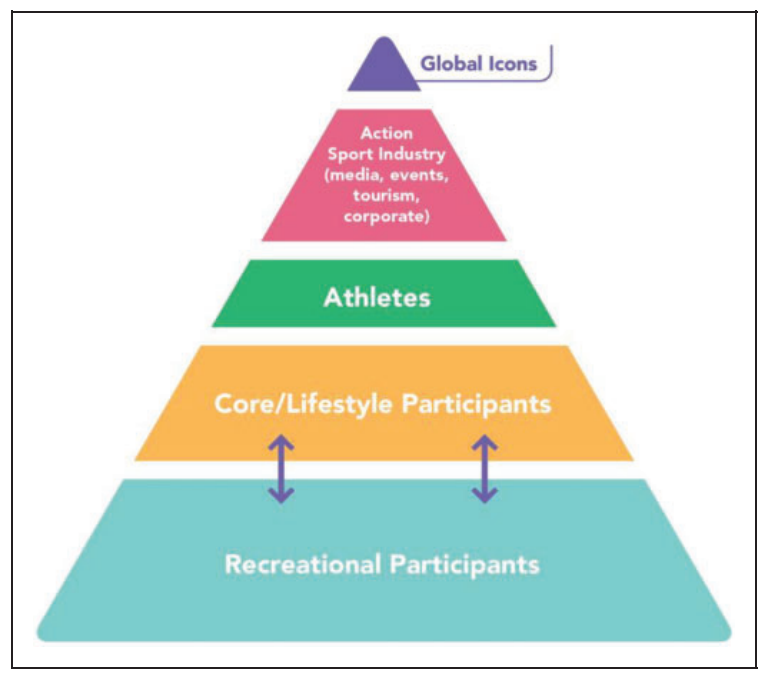

Figure I. The action sport cultural complex. ${ }^{2}$

media preferences of Gen $\mathrm{X}$ and $\mathrm{Y}$ action sport consumers and found that while Gen $\mathrm{Y}$ was more avid media consumers, the action sport genre had developed a fan base amongst both these generations. Furthermore, they acknowledge that once interest had been sparked, participants were likely to become lifelong consumers. Wheaton's (2017) work on older surfers confirms this trend.

Many youth cultures, including action sports (Wheaton, 2017), have become more "connected and compatible with adult lives," spaces where "ageing individuals continue to construct and articulate identities and claim distinctiveness in contemporary everyday life" (A. Bennett \& Hodkinson, 2012, p. 3). Recent consumer research has also revealed the quickly "graying" demographics of action sport consumers, with the median age of U.S. action sports TV viewers jumping from 31 to 47 between 2000 and 2016 (Lombardo \& Broughton, 2017). This study, however, did not include action sports online consumption, which researchers have suggested is where most young people today watch action sports (Thorpe, 2017). Nonetheless, these demographic shifts speak to the ways in which so-called youth cultures are increasingly being marketed to appeal to a wider demographic. We therefore concur with Giannoulakis and Krol Pursglove's (2017) call for more research that examines "how action sports organizations will market and engage Generation Y consumers as they get older, and yet embrace the new and up and coming Generation $Z$ youth audience" (p. 141).

\section{Method}

Our research questions emerged from a larger project focusing on the planned inclusion of new action sports into the Tokyo 2020 Summer Olympic Games 
(Wheaton \& Thorpe, 2016). This project was broadly informed by a cultural studies approach, particularly in relation to the dynamic between representation, culture, and lived experience. According to Saukko (2003), the "trademark" of the cultural studies approach to empirical research on understanding media audiences has been "an interest in the interplay between lived experiences, texts and discourses, and the social context" (Satke, 2003,p. 11). Thus, to understand the attitudes and opinions of various groups involved within and across action sport cultures and industries, we employed a multimethod approach, involving media analysis, interviews with key players in the action sport cultures and industries, and a questionnaire administered online. Each of these methods targeted the voices and opinions of different factions within the action sports cultural complex (see Figure 1). In this article, we examine action sport participants and consumers' attitudes to the inclusion of action sports in both past and future Olympic Games using data from the questionnaire and draw upon aspects of our media analysis to help contextualise these findings. The questionnaire was used to explore action sport participants' media consumption of the Olympics, and how it compared to other mediated action sport events such as the X Games and single-sport action sport competitions. While these questions framed our research, we were also attentive to any generational, gender, and national differences across each of these issues as well as differences between the different action sports.

\section{Developing Our Research Tool}

Existing research exploring action sport media consumption patterns has focused on the English speaking, and particularly North American, demographic (e.g., Kusz, 2004; Ormrod, 2009; Rinehart, 1998; Thorpe, 2011; Wheaton \& Beal, 2003). We wanted to gain a more international understanding of action sport participants' media consumption patterns beyond English speaking and North American participants, as well as participants across multiple action sports, and experiences from core participants to lifestyle consumers. The only practical approach to include participants over broad geographic locations was an online questionnaire.

As researchers working within a broadly interpretivist paradigm, the decision to use a mixed methods approach involving a quantitative method was one we initially struggled to justify epistemologically, recognising that different methodologies can create "incommensurable truths" (Saukko, 2003). However, as Elling (2015) argues, the use of such mixed methods research can have an important place in research involving comparisons across times and geographic space and in the interpretations of different media audiences.

We devised our online questionnaire to reach an international audience across multiple action sports, exploring trends in their media consumption, and the attitudes and opinions of recreational and core/lifestyle action sport consumers towards the Olympic Games (Figure 1). To ensure participants across all continents could take part, we translated the questionnaire into nine languages: Arabic, English, Portuguese, French, German, Chinese (simplified Chinese and Mandarin), Spanish, and 
Japanese. While we hoped to reveal some of the complexities, nuances, and contradictions in these consumers attitudes to action sport media consumption generally, and the Olympics specifically, we recognised the questionnaire would only give a partial picture.

All survey methods have some limitations, and while online questionnaires are comparatively new, they appear to be most effective when the target audience is technologically savvy and has access to and utilises e-mails (Olberding \& Cobb, 2007). As both Gen $Z$ and $Y$ audiences (G. Bennett \& Lachowetz, 2004) and action sport participants (Gilchrist \& Wheaton, 2013; Salome \& van Bottenburg, 2012; Thorpe, 2017) are avid users of electronic media and a wide range of digital technology, the online format seemed appropriate.

Despite using the questionnaire primarily as a data tool to help us identify key themes in media consumption patterns that we were able to explore further in interviews and media analysis, it is still important to recognise the various limitations and issues for using online surveys (Olberding \& Cobb, 2007). As we discuss below, sampling issues were relevant for this research. We also raise the potential impact of "non-response errors," which is when "non-respondents would have provided different answers to questions than those who did respond to the survey" (Olberding \& Cobb, 2007, p. 27).

Both researchers had detailed and "sensitised" knowledge of the action sport community and issues under investigation based on many years of research and participation (see Thorpe, 2011, 2014; Wheaton, 2013). This "insider" knowledge is essential in the design and development stage of the questionnaire in such specialist community contexts (Maddox, 2015). Our insider knowledge and previous research helped in developing questions deriving from both academic literature and debates in the subcultural media that would be relevant to our research objectives and be understood by this community. The questionnaire included 14 questions organised into three thematic sections: (1) action sport preference and consumption trends, (2) consumption of the Olympics and the YOG, and (3) attitudes towards the inclusion of action sport into the Olympics. Most questions offered a broad range of comprehensive responses (e.g., "I like watching the following action sports on TV and/or the Internet," with a list of action sports for the participant to check all that apply; "If you do not watch the Olympics, why not?," with list of 10 options for the participant to check all that apply), four were yes/no questions (e.g., "Do you watch the Summer Olympics?"), with only one question incorporating a Likert-type scale. Under the question, "What action sports events do you watch?," there was a list of seven broad categories of action sports events each with a Likert-type scale ranging from never to huge fan. Participants also had the opportunity to write additional comments to express their opinions, attitudes, and perceptions in most areas. These were quite extensive particularly in Chinese and English. Due to a data corruption issue, we were unable to access the Chinese comments, but 66 participants wrote comments in English ranging from a sentence to paragraphs. This engagement suggests that these are issues of interest and relevance to these participants. 
We initially piloted the questionnaire across groups of action sport consumers (including different ages and languages) and subsequently amended questions that were ambiguous. We sought assistance from our university $~$ mation and Technology Services (IT) department and researchers with extensive experience in online questionnaires in designing the tool, ensuring the questions were clear and that it worked across different browsers (including on tablets and iPads). Nonetheless, not all participants answered all of the questions and we cannot ascertain if this was because they found the question difficult to interpret or were not interested in providing a response.

Our key form of dissemination was via identified prominent action sport websites, social media, and our own action sport industry contacts developed via our respective time researching and participating in different action sports arenas (see Thorpe, 2011, 2014; Wheaton, 2013). As Maddox (2015) outlines, many communities have key "online spaces" that are important for interactions; researchers must therefore have connections to access these spaces or use relevant gatekeepers to "seed" their survey in these most appropriate places (Maddox, 2015, p. 78). As we discuss below, while our individual and collective cultural knowledge meant we had a good understanding of popular action sport media platforms, our connections were not always good enough to grant us access.

Our sample was self-selecting, based on those who had electronic access, and who were motivated to fill out the questionnaire, which can lead to bias, particularly when "the characteristics of the sample population are different from the population of interest" (Olberding \& Cobb, 2007, p. 27). Furthermore, as noted in the North American context, self-selecting samples tend to favour affluent, White men with leisure time (Maddox, 2015). Therefore, to ensure we understood who the sample was, and that it was reflective of the population of interest for our research, we asked a range of questions about their demographics (e.g., age, nationally, gender) and their sports participation and consumption. As we discuss below, the sample that chose to fill out this questionnaire was representative of the action sport consumer we had hoped to target.

The questionnaire was live for a 5-month window hosted on the University of Waikato website and completed by 820 participants. We worked with various stakeholders and contacts gained via our decades of action sports participation and research to disseminate the questionnaire as widely as possible. The 5-month window was necessary, as at various stages during this period, we took note of the countries that were underrepresented and made particular efforts to increase completions in areas where participation was initially low. We asked participants about where they heard/read about this questionnaire. "Word of mouth" was the most effective form of dissemination, with "Facebook" and "friends" accounting for over $70 \%$ of responses. As Fowler (2014) suggests, in such self-administered surveys, the intrinsic motivation of the respondent is critical. However, the dissemination via action sport websites (e.g., The Inertia, Mporia) led to minimal engagement (12\%). In fact, the editors/gatekeepers for action sport online media whom we targeted were not particularly helpful, and despite repeatedly chasing up with editors, our e-mails 
were often ignored. However, the world's largest extreme sport event organising company (International Festival of Extreme Sports [FISE]) supported the project by sharing the questionnaire at an event in China, thus contributing to our strong Chinese participation. It was only later that we learned FISE was working closely with the IOC towards the incorporation of more action sports into the Olympic Games (particularly BMX freestyle), and thus their "helpfulness" in disseminating the questionnaire may not have been purely altruistic.

As noted above, we sought to use our questionnaire to help reveal some of the complexities, nuances, and contradictions in consumer attitudes to action sport media consumption generally and the Olympics specifically. As our results seek to demonstrate sociocultural, sport-based and demographic trends in action sport media consumption, rather than make generalisations across populations, we did not conduct statistical analysis. Given our research expertise in qualitative sociology, and our interest in the multiple and diverse sport media consumption practices of action sport participants, we opted to focus on qualitative trends in the data based on our research questions and some descriptive statistics to contextualise these themes.

Our analysis also draws on a systematic collation and thematic analysis of mass and niche media sources around two moments: the short-listing of surfing, skateboarding, and sport climbing for Tokyo 2020 (September 2015 to August 2016) and immediately following the decision to include these sports (August-December 2016). We collated over 650 articles in the initial analysis phase and a further 198 articles after the announcement. The subcultural media, such as niche magazines and websites, are particularly influential in communicating attitudes and value systems within and across action sport cultures (Gilchrist \& Wheaton, 2013; Thorpe, 2017). Social media, and the dialogue and readers' comments sections in response in niche media online articles, also gave us access to the attitudes of core participants (see Figure 1) who we used to help compare, contrast, and contextualize the questionnaire results.

\section{Results and Analysis}

We begin our results and analysis by first identifying who our sample was in terms of their age, gender, nationality, and action sport consumption and participation. Following this, we explore two key themes: (1) media consumption of action sports and (2) attitudes to the inclusion of action sport in the Olympics, drawing out trends across sports, ages, nationalities, and gender.

\section{The Sample Demographic: A Snapshot of Global Youth?}

Previous research has suggested that the demographic of the typical action sport participant is male, young, and White (Kusz, 2007; Thorpe, 2014; Wheaton, 2013). Likewise, $72 \%$ of those who chose to answer the gender question of our questionnaire were male, and $28 \%$ were female. Due to a data error (caused by a problem 
with use of language scripts, particularly simplified Chinese and Mandarin), we were not able to retrieve data about ethnicity; however, their nationality was wide ranging (see below). While our questionnaire targeted action sport consumers of all ages, younger people dominated the sample: under 20s (broadly Gen Z) constituted $19 \%, 20$ - to 30 -year-olds constituted $63 \%$, and the over 30 -year-olds constituted $37 \%$ of our sample. Therefore, the sample that chose to complete this questionnaire broadly represents Gen X, Y, and Z.

The questionnaire had a wide reach with participants from all continents and 51 different countries. China was the highest ranking country with 199 participants (largely because of the Chinese event we targeted), Germany was second (81 participants), and then United States third (76 participants). Other significant countries included France (45 participants), New Zealand (42 participants), Brazil (30 participants), Japan (22 participants), United Kingdom and Switzerland (both 15 participants), Australia (14 participants), and Spain (10 participants). Despite the wide range of countries participating in the questionnaire, it is worth noting that $67 \%$ came from 11 countries, most likely as a result of both our dissemination strategies and options and countries where action sports are more popular. In terms of the language that participants chose to use to fill in the questionnaire, despite the wide range of national contexts and different languages offered, English dominated (45\%) with Chinese languages second (25\%). The remainder were, in descending order, German, French, Portuguese, Spanish, Japanese, and Arabic (1.2\%). As there is a disparity between where people lived (e.g., China ranked top), and the language used on the questionnaire (English ranked top), we might assume that some participants, particularly those living in China, were non-Chinese or, though less likely, choose to use English even though it wasn't their native language.

If using these data from a purely quantitative perspective, it could be argued that the bias in national completions skews the data, and the ambiguities around language compromise the reliability of the findings. However, as we explain above, the questionnaire was designed and implemented with a more qualitative intent - to identify and explore key trends in action sport participants consumption patterns - so for our purposes, the nationality of participants was just one variable as part of a broader complex picture of media consumption practices, which we have also explored with interviews and media analysis in the broader study.

Around three quarters of our sample were active participants in action sports; of this group, half classified themselves as regular participants in action sports (48\%) and half identified as occasional participants (52\%). As G. Bennett and Lachowetz (2004) note, many who consume action sports media and lifestyles also participate in action sports. Nonetheless, 187 people (around $22 \%$ of our sample) claimed not to participate in action sports but were interested enough in this topic to complete the questionnaire. The renterestingly, $90 \%$ of our Chinese-speaking participants stated they were nonparticipants in action sports. This supports earlier research by Rowe and Gilmour (2010) that highlights the focus on sport merchandising and consumption over participation in Asia, 


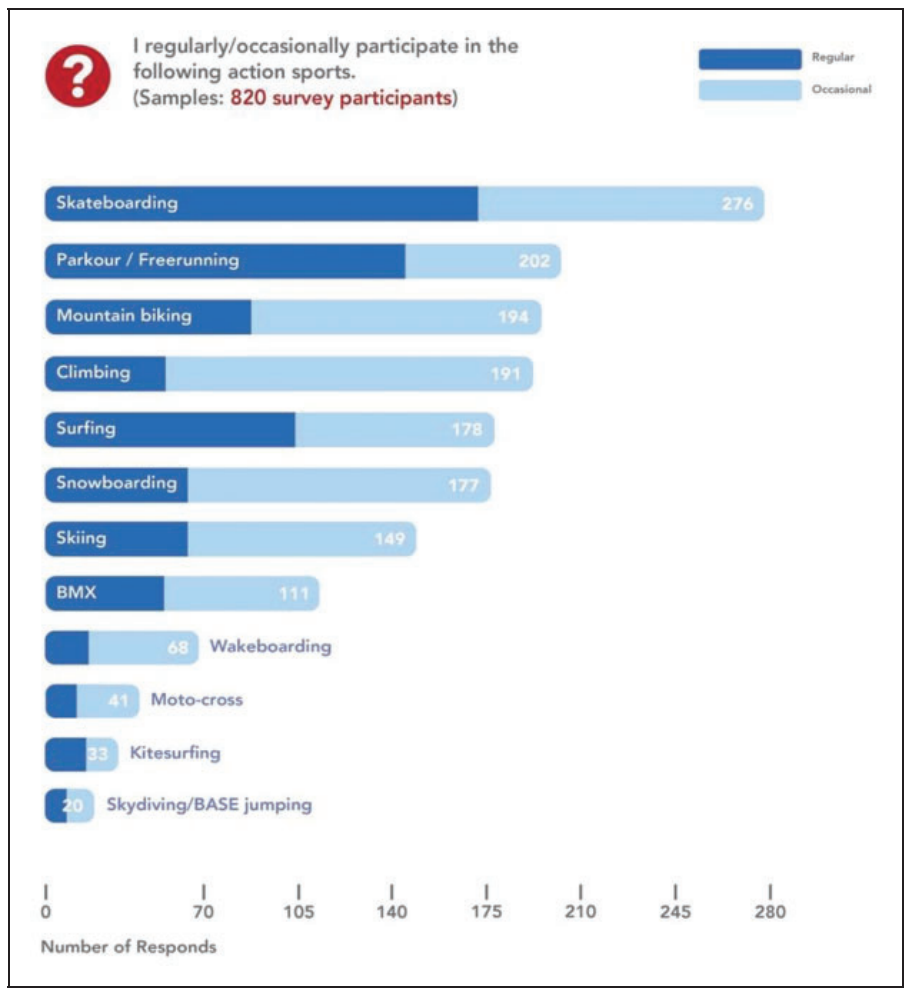

Figure 2. Questionnaire participants: Action sports participation (recreational and occasional). ${ }^{2}$

and Thorpe's $(2008,2014)$ research that explores the unique development of action sports in China and cultural differences that led to high levels of extreme sport consumption but low participation rates in China.

The active participants in our questionnaire were involved in a wide range of different action sports, as both occasional and regular participants, many participating in more than one sport (see Figure 2). The most popular activities were skateboarding (33\%, 276 participants), parkour/free running (25\%, 202 participants), and mountain biking $(23 \%, 194$ participants), closely followed by climbing (191 participants), surfing (178 participants), snowboarding (111 participants), skiing (111 participants), and BMX participants (111 participants). Smaller numbers did wakeboarding, kitesurfing, motocross, roller blading/in-line skating, skiing, and skydiving/BASE jumping. Our sample therefore represented core and marginal cultural participants (including nonparticipating consumers of action sports) across a wide range of action sports (Fimm 2), reflecting previous data about these sports, a younger male demographi 


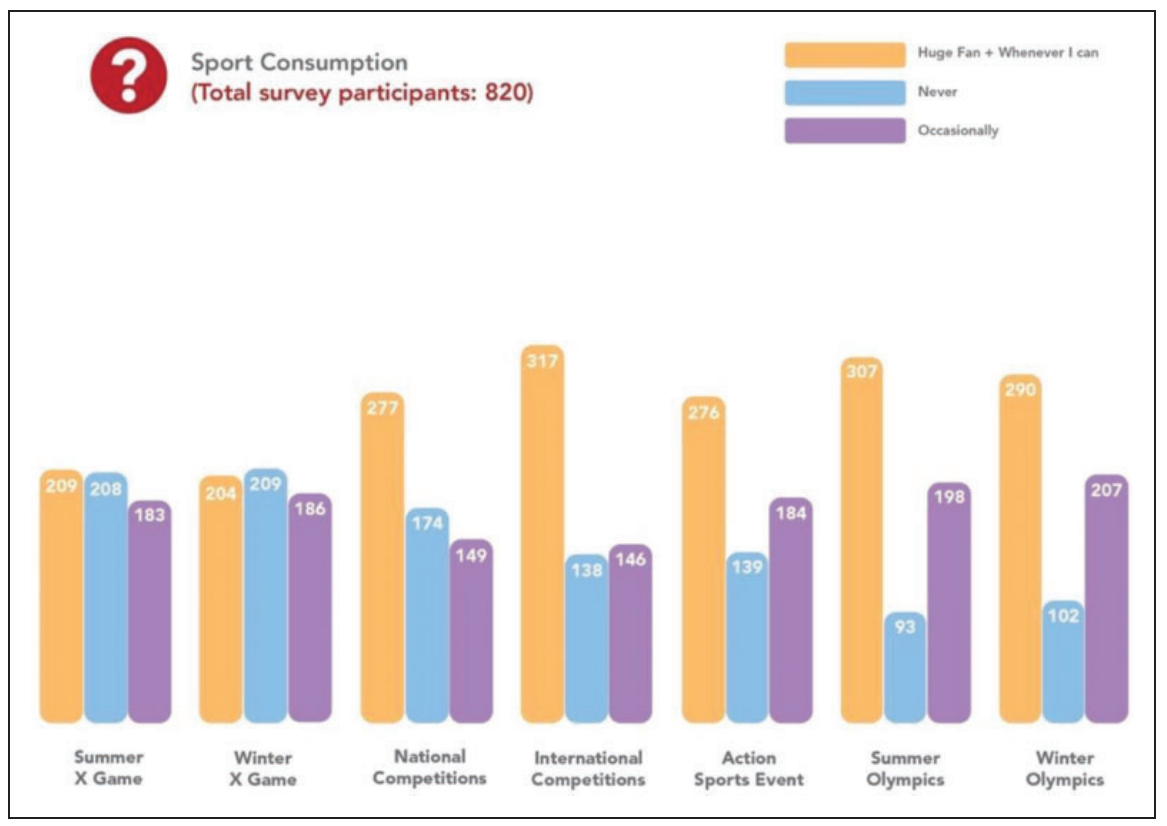

Figure 3. Questionnaire participants' sport consumption patterns. ${ }^{2}$

\section{Action Sport Media Consumption}

Research on action sport consumers and on the action sport market has highlighted the popularity and financial success of multisport action sport events like the $\mathrm{X}$ Games and single-sport events like the Vans Open (Giannoulakis \& Krol Pursglove, 2017; Smith, 2012). Furthermore, research suggests that more members of Gen Y watch action sports than their predecessors and that action sports events including the X Games were more popular amongst Gen Y media consumers in the United States than the traditional U.S. team sports of basketball and baseball and the Soccer World Cup (G.Bennett \& Lachowetz, 2004; G.Bennett et al., 2006).

Figure 3 illustrates that a range of different types of action sport events were avidly consumed by our questionnaire participants including the Summer and Winter X Games, international single action sport competitions (e.g., World Surf League), National action sporting events (e.g., Vans U.S. Open), action sport festivals (e.g., Tony Hawk and Friends Tour), and action sports competitions in the Olympics. These consumers watched action sports on a range of platforms including TV and online.

The Summer and Winter X Games were both watched by around $75 \%$ of participants, of which $25 \%$ said they were huge fans or "watched whenever they could." Within these trends, skateboarding was the most popular sport to watch (36\%; Figure 4). This was followed by parkour/free-running (31\%), snowboarding (30\%), and surfing (30\%). Our results suggest that these action sport participants/ 


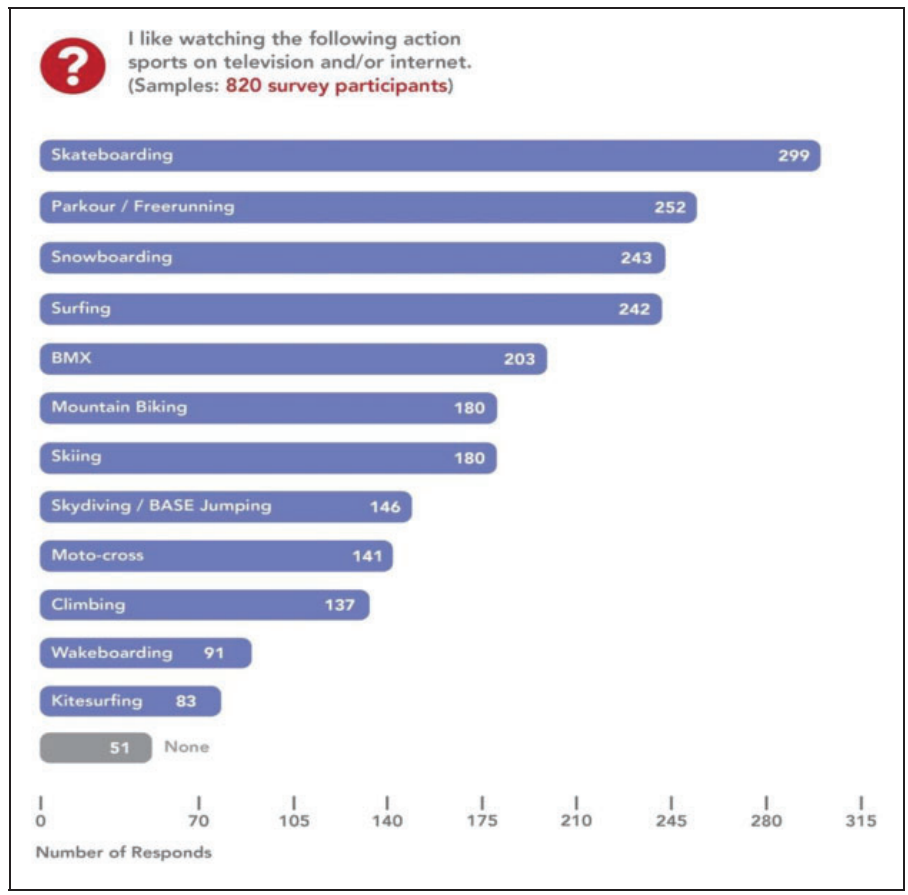

Figure 4. The action sports that questionnaire participants preferred to watch on television or the Internet. ${ }^{2}$

consumers, both core and more marginal, avidly consume a range of different action sport media competitions and events, although international single-sport competitions were the most popular.

\section{Olympic Fans? Action Sport Participants' Media Consumption of the Olympics}

Our questionnaire findings appear to differ from both previous marketing-based research and industry-based articles that suggest Gen $\mathrm{Y}$ and young action sport consumers have opted out of viewing more traditional sports, in general, and the Olympic Games, in particular. The action sport participants and lifestyle consumers in our research appear to be avid sport media consumers. The Summer Olympics and Winter Olympic Games were popular amongst these consumers, watched by $81 \%$ and $73 \%$ of respondents, respectively, that is higher viewership than the X Games but less than international action sport competitions (see Figure 3). This was somewhat surprising, given the declining viewership of the Olympics amongst youth. Yet, as discussed above, previous research looking at Olympic viewing amongst groups of action sport enthusiasts has also had mixed findings. G.Bennet et al.'s (2006) research conducted 
at an action sport event found the Olympics were less popular than the X Games or Gravity Games amongst those aged under 41. However, in contrast, G.Bennett et al. (2003) sample of high school students in North America (mean aged 15), but not specifically action sports fans or consumers, found that the Olympics were more popular $(26.1 \%)$ than the X Games (15.2\%). However, both of these studies are over 10 years old, and the action sport demographics and trends in action sport consumption have changed rapidly over this time, particularly with the availability of online media consumption options (Lombardo \& Broughton, 2017; Thorpe, 2017).

We can only speculate on some of the reasons for these differences, such as our participants covered a much broader age range and were also more international. It is also possible that those who had no interest in the Olympics did not fill in the questionnaire. For these reasons, we suggest that these percentages should be treated with some caution. Furthermore, as we discuss below, the qualitative data revealed a more complex picture that became apparent through some of the trends we identify and also the comments posted.

Our research also explored viewing preferences when watching the Summer Olympic Games (Figure 5). The most popular sports to watch were all individual activities, topped by track and field (watched by $27 \%$ ) and aquatics (watched by $25 \%$ ). Action sports were also highly placed with BMX fifth (watched by 19\%) and mountain biking (17\%), which was higher than other forms of cycling or triathlon. The least popular to watch was golf (2\%) and shooting events (4\%). At the Winter Olympics (Figure 6), snowboarding was the most popular event to watch (37\%), followed by alpine skiing (28\%), and then new skiing events such as slopestyle, half-pipe, and Skier X (24\%).

We also asked the questionnaire participants who "did not" watch the Olympics about their reasons why. A range of different responses were given. A small percentage said they "find the Olympics boring" (9.7\%) and "I don't like what the Olympics represents/stands for" (8.2\%). Only 5.5\% agreed with the statement "I don't like the style of filming and commentary in the Olympics." As noted above, the success of the X Games has been attributed in part to the more innovative forms of film and representational style, and Olympic snowboarding has also made efforts in this respect, which increased viewership (Thorpe \& Wheaton, 2017). However, the most widespread responses were "I don't have the time" (23.1\%), "the sports I am most interested in aren't in the Olympics" (19.8\%), and "the styles of sport that I am most interested in watching aren't in the Olympics" (16.7\%). It is worth noting here one of the responses given as it highlights the complexities of sport consumption trends and the need for caution around such figures:

Even though I watch snowboarding at the Olympics doesn't tell that I actually like it or [think that] it is the right movement for snowboarding. Competitive snowboarding has been in a sort of stable situation where no progress has [been] seen, thanks to the big players such as FIS and IOC. Last winter I found by accident a stream to watch the double pipe competition which offered a fresh view for snowboarding and pushed it more towards the creative direction. (Edited for clarity) 


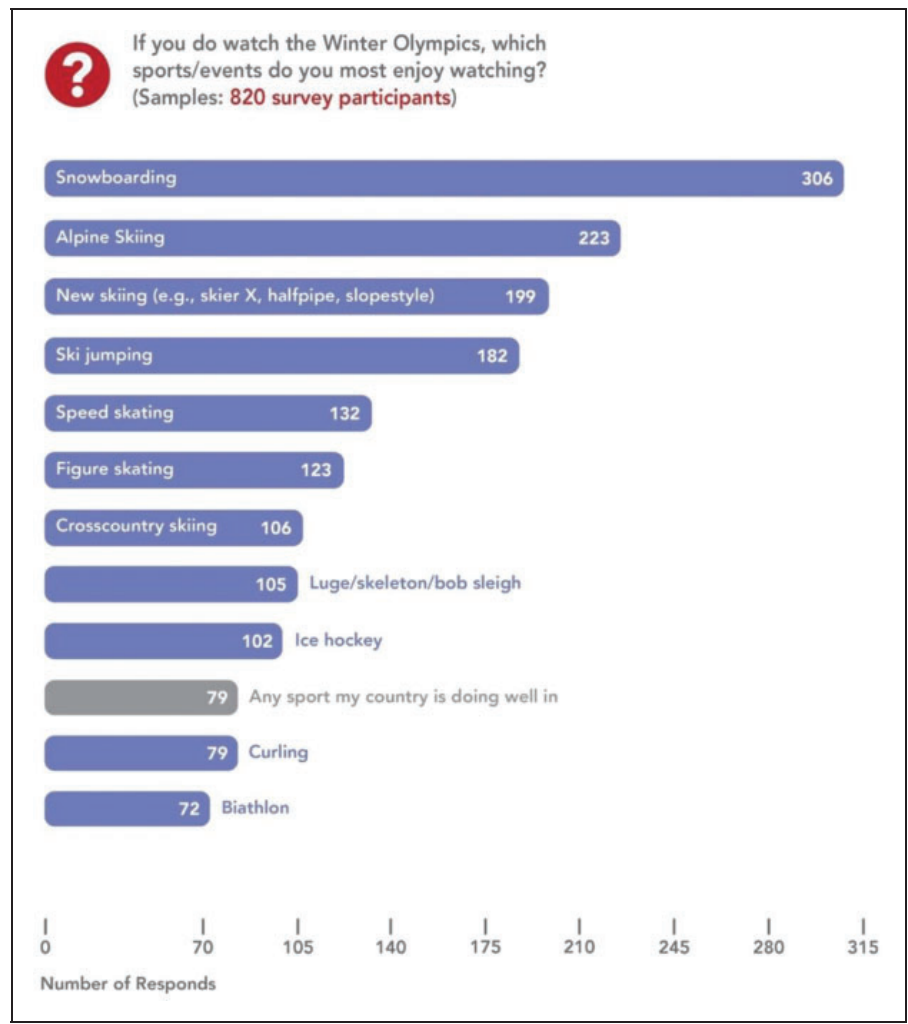

Figure 5. The sports that questionnaire participants enjoy watching at the summer Olympic games. $^{2}$

As we discuss further below, this quote highlights that while action sport participants avidly consume their sports including at the Olympic Games, it does not mean they necessarily agree with how they are represented or the direction taken when these sports are included in the Olympic Games.

Despite the widespread belief that men's sport attracts greater audiences, when asked whether they preferred watching male or female events, the majority enjoyed both. Only 7.4\% agreed with the statement "I prefer watching men's events at the Olympics." It is also interesting to note that in line with previous research on action sports (Thorpe, 2014; Wheaton, 2005), participants tended not to affiliate with athletes or events along nationalist lines. In many cases, action sports athletes at the Olympics have gained little or no funding from their nations, with their primary sources of financial support coming from corporate sponsors. Thus, many action sport athletes tend to affiliate more with their sponsors "teams" (which are often a combination of national and international athletes sponsored by the same company) 


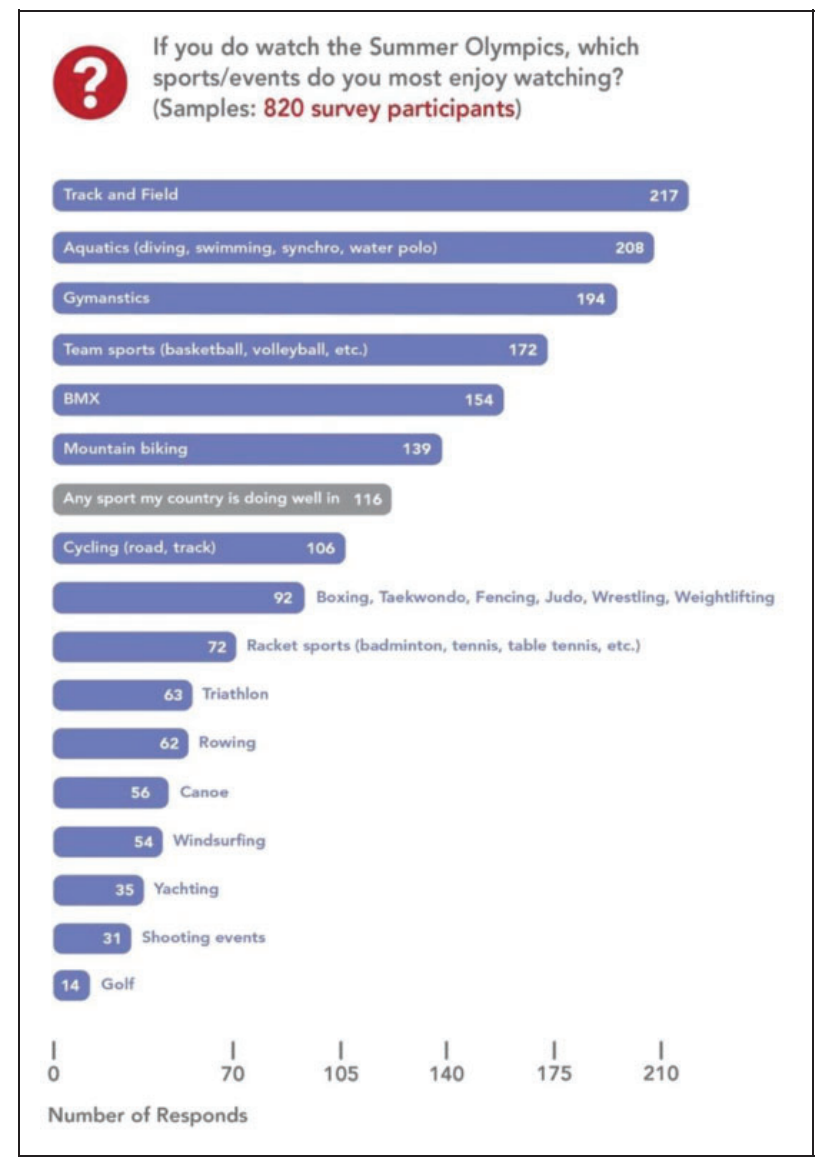

Figure 6. The sports that questionnaire participants enjoy watching at the winter Olympic games. $^{2}$

rather than their national team (Thorpe \& Wheaton, 2011a). Only $4.5 \%$ of respondents stated that "I have no preference when my country is doing well," suggesting that few watched the Olympics with a purely patriotic lens.

\section{Attitudes to the Inclusion of Skateboarding, Surfing, and Sport Climbing in Tokyo 2020}

As discussed in the review of literature, Olympic inclusion has been a contested process, with much scepticism and dissent from the core of the sporting cultures (Humphreys, 2003; Thorpe \& Wheaton, 2011a, 2011b). Our analysis of the subcultural media illustrated that these anti-Olympic sentiments were also widespread in response to the Tokyo proposals. For example: 
Someone please drown this whole $\mathrm{f}^{* *}$ king idea, surfing doesn't need this shit.... We don't need more surfers and more popularity .... The only ones who benefit from this shit are the big brands selling more crap gear from sweat shops in 3rd world countries. (Comment posted on Surf Line)

No!!!!! No no no no no. Please stop perpetuating the mainstream direction of these two lifestyles ... Dammit!!!!!!! (Comments on http://Outsideonline.com in response to the announcement climbing is to be considered for inclusion in Tokyo 2020)

Nonetheless, the subcultural media analysis revealed a range of viewpoints from those who were wholly supportive (e.g., seeing the potential benefits for action sport athletes and governing bodies) to these long-term "core" participants, who often remain ardently anti-Olympics. The dominant discourse, however, was one of concern and measured scepticism, raising a broad range of concerns about the process and impact on the cultures of their sports.

When our questionnaire went live, the sports of skateboarding, surfing, and sport climbing had been shortlisted but not yet ratified for inclusion in Tokyo 2020 (official announcement was August 3, 2016). Our questions therefore asked about attitudes to the future potential inclusion of action sports in the Olympics. Of our participants, $60 \%$ felt the inclusion of more action sports was a good idea and that it would encourage them to watch more of the Olympics. As we were particularly interested to see if younger consumers held different attitudes to the Olympics, we mapped out attitudes across five age bands: under 19, 20-30, 31-40, 41-50, and over 50s. The youngest participants (under 19) were most enthusiastic about action sports inclusion in the Olympics; $80 \%$ of whom said "I think this is a great idea and I would likely watch more of the Olympics." This is a strong endorsement of the Gen $\mathrm{Z}$ and Ys action sports participants/consumers attitudes towards the Olympic Games. Moreover, this age-group has grown up in a context where action sports have always been part of mega events such as the X Games and the wheels of commodification and institutionalization have long been in process, thus they tend not to cling to memories of action sports precommercialisation (Beal \& Wilson, 2004). In contrast, only around half (54\%) of the 20 - to 40 -year-olds were "likely to watch more of the Olympics" if action sports were included. The percentage was a little higher for the over 50s (65\%), the age-group that has been the core Olympic audience. The agegroup most likely to say "I dislike what happens to action sports when they become Olympic sports" were the 20-40s (27\%), whereas over 50s (15\%) and under $19 \mathrm{~s}$ (12\%) were less concerned. These findings further support claims that there are generational shifts in attitudes toward the Olympics. Our broader project findings support the questionnaire in suggesting that core male participants aged 20-40 are those mostly likely to contest action sports inclusion in the Olympics, perhaps because they have the most to lose in terms of control of their sporting culture and industry. In terms of gender differences, attitudes to Olympic inclusion were broadly similar across men and women. However, a greater percentage of men than women 
(25\% vs. $16 \%$ ) "disliked what happens to action sports when they become Olympic sports"; and more women than men said that they "don't really care."

However, clear national differences in attitudes to Olympic inclusion were apparent based on comparing the three most common languages amongst our questionnaire participants. The Chinese speakers were most supportive of Olympic inclusion (84\%), with only a very small percentage expressing strong anti-Olympics sentiments $(2 \%)$. In contrast, only $17 \%$ of the German speakers thought it was a "great idea," and 59\% said they "disliked what happened to action sports when they became Olympic Sports.” The English speakers (representing United States, Australia, New Zealand, England, and others) had a less polarised view with 56\% saying "I think this is a great idea and I would likely watch more of the Olympics" and 26\% stating "I dislike what happens to action sports when they become Olympic sports."

The written commentary was informing in revealing some of the attitudes underlying these trends. Those endorsing the inclusion of action sports pointed to them being exciting to watch, enhancing the Olympic programme, and bringing it "up to date." For example:

Action sports often require a lot more training than other "normal" sports. And not only that. It also takes courage and bravery so I think that the Olympic spirit is more represented by this kind of sport. Action sport got that "plus" that always amaze people more than, just for example, the 1,000 $\mathrm{m}$ crawl of swimming.

It was also argued that Olympic inclusion would give the action sports more visibility; and credibility, and it was assumed facilitate more funding to the athletes to allow "hardworking individuals to be able to make a living." Noting the benefits of inclusion, one questionnaire participant added, "any sport being added to the Olympics increases it reputation and applicability to the general public and boost[s] the funding and long-term support for the sport."

Nonetheless, the written commentary painted a complex picture. For example, some respondents, while broadly supportive, did show an attentiveness to the potential problems for the action sport cultures, such as cultural clashes between their ethos and that of the Olympics (see Thorpe \& Wheaton, 2011b). According to one questionnaire participant, "In some ways adding the sport to the Olympics legitimizes the sport, giving it more respect in the community but I think that this also has negative effects on the culture of the sport." Furthermore, reflecting debates in the subcultural media, questionnaire participants also expressed concerns about action sports commercialisation and institutionalisation, "selling-out" action sport's alternative ethos and heritage (Humphreys, 2003). A large proportion of the English commentary highlighted these concerns. For example:

Incorporating these sports into the Olympics undermines what some people want them to stand for, alternatives, nonnationalistic, art forms. 
Action sports are individual activities that are fun and promote individual development and community building. Turning them into competitive spectacles that ultimately involve money and sponsorships is a perversion of the soul of the activity, and benefits the sponsoring entity, the commercial sponsor or the IOC, but not the spirit of the activity itself. [...] ] It is sad to see the politics, maneuvering, greed and manipulation that goes on behind the scenes of what is promoted as an altruistic opportunity for great athletes to compete for the "gold." It is truly a sign of the times.

Others argued that the Olympic movement to date had not demonstrated the ability to preserve nontraditional sport's difference and creativity:

Every real-world activity that has been introduced into the Olympic games seems to eventually lose sight of why the sport/activity was developed in the original sense. Taekwondo for example has become less of an actual "martial" art and more about the flashy kicks that everyone wants to see. I don't see a good ending to some of these activities if entered in to the Olympics. (Comment in response to answer to "I dislike what happens to action sports when they become Olympic sports")

Some respondents were wholly critical of the Olympic Games:

"Action sports" don't belong in the out-dated Olympic games, the greed and pride of nations shown during the Olympics is a farce.

Olympics represent everything evil about $s_{\mathrm{r}} \ldots . . . .6$. Action sports have always been somehow "rebel" in a good way. They have always said "hell no" if someone wants them to be part of something they feel hard to represent. In the end, Olympics is the biggest NO to represent. With that in mind, not only every action sport should get rid of Olympics but also the whole Olympic movement should vanish.

In summary, a wide range of views was evident, including these more vociferous anti-Olympic sentiments. Yet, in contrast to the "core" voices represented in the subcultural media (often in articles written by action sports journalists, athletes, and other cultural spokespersons and comments sections dominated by the "angry" voices of core participants), these more recreational lifestyle participants represented in our questionnaire were more in favour of, and excited about, action sports Olympic inclusion. This was particularly evident amongst Chinese-based consumers and the under $19 \mathrm{~s}$, two groups with less connection to the unique cultural histories and early ethos (i.e., countercultural, antiestablishment) of these sporting cultures.

\section{Action Sport Popularity: Trends Across Sports and Generations}

The international skateboarding community has been very vocal about its concerns regarding Olympic inclusion, so it was somewhat surprising that the sport that questionnaire participants most wanted to see in future Olympics was 


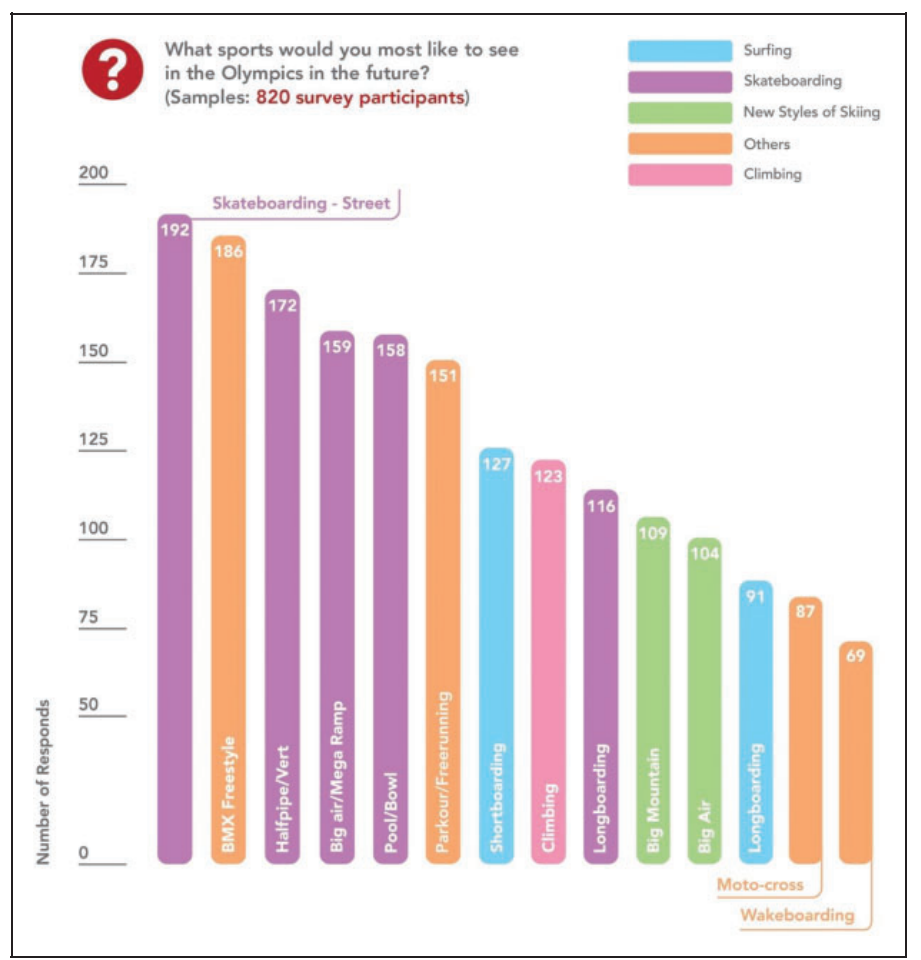

Figure 7. The action sports that questionnaire participants most want to see in future Olympic games. ${ }^{2}$

skateboarding (Figure 7), with street skating as the most popular style (36\% of respondents).

All other forms of skateboarding, except longboarding, were in the top 5, including half-pipe/vert (21\% of respondents), big air/mega ramp (19.3\% of respondents), and pool/bowl (19.2\% of respondents). Street skateboarding was most popular with those aged under 20s; each of the top 5 ranked sports for the under 19s was a style of skateboarding. In contrast, surfing (short board) was popular with older participants, ranked second with the over 40 s, but not so popular with younger participants. These findings illustrate a strong endorsement of skateboarding by these action sport participants and consumers, and particularly Gen Y and Z. As one questionnaire participant wrote, "skate street style is a new discipline NBC does on their Dew Tour-very exciting, " " 'aters love it... X Games does not do it." Other popular action sports included $\int$ (23\%), 20 50, and parkeur/free rumning (18\%). Elimbing and short beard-surfing were less poptar (15\% ef of oller blading was not one of the categories on the questionnaire, numerous comments suggested that roller blading 
and aggressive in-line skating were considered popular amongst this group. For example, one participant added the comment: "include inline skating to the list, bigger jumps and longer grinds than most extreme sports."

However, given this was a self-selecting sample, and that popularity was likely to be influenced by the action sports that our sample practiced or watched, we also examined trends across action sports. Broadly, we found that action sports participants in this research supported the inclusion of the sport(s) they participated in. For example, despite the antiestablishment message that we found prevalent across skate niche media, of those who said they were regular or occasional skateboarders (228 people in our sample), skateboarding was the action sport they would most like to see in the Olympics, with $56 \%$ of skateboarders preferring street, $47 \%$ pool/bowl, 37\% half-pipe/vert, and $43 \%$ big air/mega ramp. Skaters also supported BMX freestyle and parkour. Surfing was less popular among skateboarding questionnaire participants (only $24 \%$ endorsed it) and climbing was only supported by $14 \%$.

Likewise, for the climbers in the sample (179 in total), climbing was the sport they would most like to see it in future Olympic Games (39\%), closely followed by parkour/free running (29\%). For the surfers in the sample (164 people), short-board surfing was their first-ranked preference, followed by skateboarding, with "street" being marginally the most popular style followed by half-pipe/ bowl and big air/mega ramp. Long-board surfing and Stand Up Paddleboarding (SUP) were much less popular than short-board surfing. Surfing in a wave pool was unpopular amongst surfers, coming second to last with only 34 people (20\%) supporting its inclusion. As we discuss elsewhere (Wheaton \& Thorpe, 2016) and has been widely debated in surfing's niche media (Evers, 2016), at the time of the questionnaire, wave pools were highly controversial amongst the surfing community. As one participant wrote:

I'm a 3-time National Surfing Champion and I'm not a fan of adding surfing to the Olympics especially in a wave pool. Wave pool surfing is entirely different than dealing with the elements in the ocean.

However, there were also some important differences nationally in the sports that participants most wanted to see in the Olympics. For example, urban sports, particularly skateboarding styles, were the most popular sport for our Chinese speakers. The English speakers favoured a range of action sports with skateboarding and surfing ranked first equal. This finding reflects previous research in the United States that found that, of the summer-based act:- sports, surfing was most popular (17.1\%) with skateboarding second (10.6\%. iennett et al., 2003). In our results, short-board surfing was ranked first equal amongst English speakers but was not ranked by either the Chinese or German speakers. To understand the reasons for these differences, further in-depth qualitative research is required across different national contexts. 


\section{Discussion}

This research has contributed to understandings of action sport consumers' sport media preferences across generations and geographic locations and to the relationship between action sport and the Olympic Games. To date, much of the literature (predominantly based in the United States) has suggested that Gen Y consumers dominate action sports. Our research also suggests that Gen $\mathrm{Y}$ and $\mathrm{Z}$ are avid consumers of action sports as participants, and in media consumption, however, interest is not confined to youth. Many Gen-X action sport consumers continue to participate avidly in the action sport lifestyle. Building upon G.Bennett et al. (2006), our study suggests that action sports have a fan base amongst Gen X, Y, and Z.

Our research also suggests that these action sport participants across different continents, ages, and genders are avid consumers of sport media involving both traditional and action sports and on a range of platforms. Popular media events included international and national action sport competitions, such as the World Surf League and Summer and Winter X Games. Skateboarding was the most popular sport to watch amongst our participants. Although skateboarders were overrepresented in our questionnaire, it was also popular amongst other action sport participants. In contradistinction to previous research that suggests youth are increasingly disinterested in the Olympic Games, the action sport participants/consumers in our study do watch the Summer and Winter Olympics and proclaimed to enjoy a range of events including traditional sports (e.g., track and field) and action sports (e.g., BMX, snowboarding, new forms of skiing, mountain biking).

Yet the ways in which individuals consume these sports and the pleasures they gain may differ to more traditional sports fans. For example, action sport participants tended not to affiliate with athletes or events across nationalist lines. Reflecting previous research on the Olympics and their gendered audiences (Wensing \& Bruce, 2003), female competitions were just as popular as male ones. The action sport enthusiasts in our research did not prefer watching men's sport to women's sport in the Olympics. However, women were more enthusiastic than men about action sports being included in the Olympics, particularly for certain sports (e.g., surfing, kitesurfing, parkour). Elsewhere we argue that the inclusion of action sports into the Olympic Games has been more contested by male participants, particularly those who stand the most to lose by greater diversity and changing power relations in their sporting cultures and industries (Wheaton \& Thorpe, in press).

In terms of the proposed inclusion of surfing, skateboarding, and sport climbing into Tokyo 2020, the quantitative data appear to endorse the IOC's hopes that action sport consumers will be interested in watching their sports in the Olympic. Of the 820 questionnaire participants, $60 \%$ thought that the inclusion of more action sports was a good idea and would probably lead them to watch more of the Olympics. The inclusion of street skateboarding was the most popular choice among questionnaire correspondents. This finding parallels a recent report that showed skateboarding in the top 5 sports American youth want to try, including Latino and Black youth 
(Aspen Institute Project Play, 2018). For our questionnaire participants, all forms of skateboarding were popular, as was BMX freestyle. There were, however, some important differences and trends across ages and nationalities. The under 19s (Gen Z) were most enthusiastic about action sports being included in the Olympics: $80 \%$ of under 19s supported it, and skateboarding was most popular. There were also differences nationally, particularly that Chinese- and English-speaking countries differed in their sport media consumption preferences. This finding suggests that research on U.S.-based action sport audiences may not be generalizable to other locales. We should therefore remain cautious in the claims we make about the homogeneity of the action sport consumer. Building upon earlier research that reveals how action sports developed differently in China (largely top-down processes driven by U.S. companies and the Chinese government; Thorpe, 2008, 2014), and the predominance of sport merchandising, consumption over participation in Asia (Rowe \& Gilmour, 2010), additional research that examines the contextual differences in action sport participation and consumption patterns across nations will prove valuable for understanding the national differences signalled in this questionnaire.

Reflecting research exploring the Olympic inclusion of previous action sports such as snowboarding, BMX racing, and windsurfing (Thorpe \& Wheaton, 2011a, 2011b), and debate in the subcultural media, participants also have concerns about how action sports are being represented by traditional sports organizations and mainstream media companies. Many participants took the opportunity provided by the "comments" sections to offer more colourful arguments for/against the inclusion of action sports into the Olympic Games, which provided a more nuanced understanding of this issue. The viewpoints of the more recreational and occasional questionnaire participants differed in options and attitudes to frequent core participants. This suggests that the views being expressed in the subcultural media, and indeed on forums, are only one part of the picture. As previous research has revealed, action sport cultures are highly fragmented and fast changing (Thorpe \& Wheaton, 2013), yet the diversity of opinions about Olympic inclusion has not been presented in the subcultural media which tend to prioritise the voices of athletes and core cultural participants. Thus, in sharing the perspectives of recreational and occasional action sport participants, this article adds to current understandings of the politics of Olympic inclusion for the broader action sports community beyond the core.

Despite some epistemological reservations about the value of the questionnaire, it provided quantitative and qualitative data to explore media consumption trends particularly across different age-groups, action sports, and international contexts. The nature of this self-selecting sample, with participants primarily being selfdeclared action sport enthusiasts, means that we need to be cautious in interpreting our quantitative claims such as the size of the groups supporting Olympics inclusion. However, the questionnaire has revealed some important new trends in understanding contemporary action sport media consumption and in action sport participants' attitudes to the Olympics. To ascertain if these findings are meaningful, more 
detailed qualitative research is required to understand the motives and meanings behind these differences, particularly to understand the national differences. Furthermore, the questionnaire results (and gaps) highlight the need for qualitative research exploring how variables such as age, gender, nationality, sport, and participation and commitment levels intersect to influence sport media consumption patterns.

\section{Conclusions}

In sum, this research provides valuable information about the media preferences of action sport consumers, and their attitudes to action sports inclusion in the Olympic Games. There is clear enthusiasm for a broad variety of action sport media amongst Gen X, Y, and Z. We have demonstrated some differences across ages, with the under $19 \mathrm{~s}$ - broadly aligning with Gen $\mathrm{Z}$ - being the most enthusiastic about action sports in the Olympics and most enthusiastic about skateboarding in particular. The study, which is best seen as a groundwork mapping of international, generational, and cross-sport trends, highlights many areas for further in-depth qualitative research. While the marriage between action sports and the Olympic Games may well provide the IOC with new viewers and lucrative markets, to maximise the engagement of those complex intergenerational and cross-cultural audiences, their viewing preferences will need continued attention and understanding.

\section{Declaration of Conflicting Interests}

The author(s) declared no potential conflicts of interest with respect to the research, authorship, and/or publication of this article.

\section{Funding}

The author(s) disclosed receipt of the following financial support for the research, authorship, and/or publication of this article: Research conducted with an IOC Advanced Research Programme Grant (2015).

\section{Note}

1. For example, in the sport marketing literature, Walker, Soroka, and Kellett (2005) and G. Bennett and Lachowetz (2004) draw on the work of Howe and Strauss (2000), who characterise Generation Y as individuals born between 1982 and 2003.

2. The figures were produced in color, and important detail may be lost in the grey scale reproduction. The full color images are available in the online version.

\section{References}

Aspen Institute Project Play. (2018, April). State of play Harlem. Retrieved from https:// assets.aspeninstitute.org/content/uploads/2018/04/HarlemSOP_FINAL_4.9.18.pdf

Bauder, D. (2010, February 16). Olympics prove popular with TV viewers. Times Free Press. Retrieved from http:/www.timesfreepress.com/news/olympics2010/story/2010/feb/16/ olympics-prove-popular-tv-viewers/5958/ 
Beal, B., \& Smith, M. (2010). Maverick's: Big-wave surfing and the dynamic of "nothing" and "something". Sport in Society: Cultures, Commerce, Media, Politics, 13, 1102-1116.

Beal, B., \& Weidman, L. (2003). Authenticity in the skateboarding world. In R. Rinehart \& S. Sydnor (Eds.), To the extreme: Alternative sports inside and out (pp. 337-352). Albany: SUNY Press.

Beal, B., \& Wilson, C. (2004). "Chicks dig scars": Commercialisation and the transformations of skate boarders' identities. In B. Wheaton (Ed.), Understanding lifestyle sports: Consumption, identity and difference (pp. 31-54). London, England: Routledge.

Beall, G. (2016, November 5). 8 Key differences between Gen Z and millennials [Blog post]. Retrieved from https://www.huffingtonpost.com/george-beall/8-key-differencesbetween_b_12814200.html

Bennett, A. (2011). The post-subcultural turn: Some reflections 10 years on. Journal of Youth Studies, 14, 493-506.

Bennett, A. \& Hodkinson, P. (Eds.). (2012). Ageing and youth cultures: Music, style and identity. London, England: Berg.

Bennett, G., Henson, R., \& Zhang, J. (2003). Generation Y's perceptions of the action sports industry segment. Journal of Sport Management, 17, 95-115.

Bennett, G., \& Lachowetz, T. (2004). Marketing to lifestyles: Action sports and Generation Y. Sports Marketing Quarterly, 13, 329-243.

Bennett, G., Sagas, M., \& Dees, M. (2006). Media preferences of action sports consumers: Differences between Generation X and Y. Sport Marketing Quarterly, 15, 40-49.

Bialik, C. (2002, February 3). NBC's bid to woo young to Olympics. Media Life Magazine. Retrieved from http://www.medialifemagazine.com:8080/news2002/feb02/feb04/5_fri/ news3friday.html

Billings, A. (2008). Olympic media: Inside the biggest show on television. London, England: Routledge.

Billings, A. (2011). Sports media: Transformation, integration, consumption. New York, NY: Routledge.

Booth, D. (2008). (Re)reading the Surfers' bible: The affect of tracks continuum. Journal of Media and Cultural Studies, 22, 17-35.

Bridges, P. (2014). Interview: Terje Haakonsen talks the arctic challenge 2014, the Olympics, and riding switch at the Mt. Baker Banked Slalom. Snowboarder. Retrieved from https://www. snowboarder.com/featured/interview-terje-haakonsen-arctic-challenge-2014-olympics/

Butler, N. (2017). Changing the Olympic programme is rather fun but a classic example of sport politics at play. Inside the Games. Retrieved from https://www.insidethegames.biz/ articles/1049321/nick-butler-changing-the-olympic-programme-is-rather-fun-but-a-clas sic-example-of-sport-politics-at-play

Chang, C. (2016, August 17). How the Olympics lost millenials. New Republic. Retrieved from https://newrepublic.com/article/136096/olympics-lost-millennials

de Moraes, L. (2018). Shaun White's gold lands NBC's highest Pyeong Chang Olympics ratings peak to date. Retrieved from http://deadline.com/2018/02/shaun-white-gold-nbchighest-pyeongchang-olympics-ratings-peak-to-date-1202288095/ 
Dillman, L. (2010, February 20). Snowboarding goes from X Games to A-list. Los Angeles Times. Retrieved from http://articles.latimes.com/2010/feb/20/sports/la-sp-olympics-Xsports20-2010feb20

Edwards, B., \& Corte, U. (2010). Commercialization and lifestyle sport: Lessons from 20 years of freestyle BMX in "Pro-Town, USA". Sport in Society: Cultures, Commerce, Media, Politics, 13, 1135-1151. Retrieved from https://doi.org/10.1080/17430 431003780070

Elling, A. (2015). Assessing the sociology of sport: On reintegrating quantitative methods and gender research. International Review for the Sociology of Sport, 50, 430-436.

Evers, C. (2016). Why adding surfing to the Olympic Games is bad news for surfers: From where I stand. Huck Magazine. Retrieved from http://www.huckmagazine.com/perspec tives/surf-olympics-bad-idea/

Flint, J., \& Vranica, S. (2016, August 14). NBC's ratings for Rio Olympics fall behind London. Wall Street Journal. Retrieved from https:/www.wsj.com/articles/nbcs-ratingsfor-rio-olympics-fall-behind-london-1471185907

Fowler, F. (2014). Survey research methods (5th ed.). Los Angeles, CA: Sage.

Giannoulakis, C., \& Krol Pursglove, L. (2017). Evolution of the action sports setting. In S. E. Klein (Ed.), Defining sport: Conceptions and borderlines (pp. 128-146). Lanham, MD: Lexington Books.

Gilchrist, P., \& Wheaton, B. (2013). New media technologies in lifestyle sport. In B. Hutchins \& D. Rowe (Eds.), Digital media sport: Technology and power in the network society (pp. 169-185). New York, NY: Routledge.

Haaksonsen, T. (2014). Why I still hate the Olympics. Whitelines. Retrieved from https://white lines.com/archive/features/debate/terje-haakonsen-why-i-still-hate-the-olympics.html

Honea, J. C. (2013). Beyond the alternative vs. mainstream dichotomy: Olympic BMX and the future of action sports. Journal of Popular Culture, 46, 1253-1275. Retrieved from https://doi.org/10.1111/jpcu.12087

Howe, N., \& Strauss, W. (2000). Millennials rising: The next generation. New York, NY: Random House.

Humphreys, D. (2003). Selling out snowboarding: The alternative response to commercial cooptation. In R. Rinehart \& S. Sydor (Eds.), To the extreme: Alternative sports, inside and out (pp. 407-428). Albany: State University of New York Press.

Jones, I. (2016, August 3). IOC approves five new sports for Olympic Games Tokyo 2020. Retrieved from https:/www.olympic.org/news/ioc-approves-five-new-sports-for-olym pic-games-tokyo-2020

Kellett, P., \& Russell, R. (2009). A comparison between mainstream and action sport industries in Australia: A case study of the skateboarding cluster. Sport Management Review, 12, 66-78. Retrieved from https://doi.org/10.1016/j.smr.2008.12.003

Kusz, K. (2004). "Extreme America": The cultural politics of extreme sports in 1990s America. In B Wheato. (Ed.), Understanding lifestyle sports: Consumption, identity and difference (pp. 197-213). London, England: Routledge.

Kusz, K. (2007). Revolt of the white athlete: Race, media and the emergence of extreme athletes, in America NY: Peter Lang Publishing. 
Lines, G. (2000). Media sport audiences-young people and the summer of sport ' 96 : Revisiting frameworks for analysis. Media, Culture \& Society, 22, 669-680. Retrieved from https://doi.org/10.1177/016344300022005008

Lombardo, J., \& Broughton, D. (2017, June 5-11). Going gray: Sports TV viewers skew older. Street and Smith's Sports Business Journal. Retrieved from http://www.sportsbusinessda ily.com/Journal/Issues/2017/06/05/Research-and-Ratings/Viewership-trends.aspx

Maddox, A. (2015). Research methods and global online communities: A case study. Farnham, England: Ashgate.

Mellgren, D. (1998, January 7). AP reports Terje boycotting Nagano? SOL Snowboarding Online. Retrieved from https://snowboarding.transworld.net/news/ap-reports-terje-boycot ting-nagano/

Muggleton, D. \& Weinzierl, R. (Eds.). (2003). The post-subcultures reader. Oxford, England: Berg

Olberding, D. J., \& Cobb, S. (2007). On-line and telephone surveys: The impact of survey mode on spending estimates by participants in a major urban marathon. The ICHPER-SD Journal of Research in Health, Physical Education, Recreation, Sport \& Dance, 2, $27-32$.

Ormrod, J. (2009). Representing "authentic" surfers identities in "Pure" surf films. In J. Ormond \& B. Wheaton (Eds.), "On the edge": Leisure, consumption and the representation of adventure sport. Eastbourne, England: Leisure Studies Association.

Ourand, J., \& Karp, A. (2012, March 19). Which sport can say: We are young. Street and Smith's Sports Business. Retrieved from http://www.sportsbusinessdaily.com/Journal/ Issues/2012/03/19/Media/Sports-demos.aspx

Peck, S. (2007, June 8). 2012 Games could see skateboarding debut. The Telegraph. Retrieved from http://www.telegraph.co.uk/news/uknews/1553957/2012-Games-could-see-skate boarding-debut.html

Popovic, M., \& Morrow, D. (2008). Stomping the shadow: The elevation of snowboarding to the Olympic pedestal from a Jungian perspective. Sport History Review, 39, 170-191. Retrieved from https://doi.org/10.1123/shr.39.2.170

Rinehart, R. (1998). Sport as constructed audience: A case study of ESPN's the eXtreme games. In R. Rinehart (Ed.) Players all: Performances in contemporary sport (pp. 84-97). Bloomington: Indiana University Press.

Rinehart, R. (2008). ESPN's X games, contests of opposition, resistance, co-option, and negotiation. In M. Atkinson \& K. Young (Eds.), Tribal play: Subcultural journeys through sport (pp. 175-196). Bingley, England: Emerald JAI.

Rinehart, R. \& Sydor, S. (Eds.). (2003). To the extreme: Alternative sports, inside and out. Albany: State University of New York Press.

Rowe, D., \& Gilmour, C. (2010). Sport, media and consumption in Asia: A merchandised mileu. American Behavioral Scientist, 53, 1530-1548.

Salome, L., \& van Bottenburg, M. (2012). Are they all daredevils? Introducing a participation typology for the consumption of lifestyle sports in different settings. European Sport Management Quarterly, 12, 19-42. Retrieved from https://doi.org/10.1080/16184742. 2011.637171 
Saukko, P. (2003). Doing research in cultural studies: An introduction to classical and new methodological approaches. London, England: Sage.

Smith, C. (2012, October 19). The dew tour changes, but mountain dew remains a top action sports brand. Forbes. Retrieved from https://www.forbes.com/sites/chrissmith/2012/10/ 19/mountain-dew-gains-untold-action-sports-legitimacy-with-dew-tour/\#506d22b75bbe

Sugden, J. \& Tomlinson, A. (Eds.). (2011). Watching the Olympics: Politics, power and representation. London, England: Routledge.

The Petition, No Skateboarding in the Olympics! (2010). Retrieved from http://www.thepeti tionsite.com/takeaction/656763888? $1 \mathrm{tl}=1146760863$

Thorpe, H. (2008). Extreme sports in China. In F. Hong, D. Mackay, \& K. Christensen (Eds.), China Gold: China's quest for global power and Olympic glory. Great Barrington, MA: Berkshire.

Thorpe, H. (2011). Snowboarding bodies in theory and practice. Basingstoke, England: Palgrave Macmillan.

Thorpe, H. (2014). Transnational mobilities in action sport cultures. New York, NY: Palgrave Macmillan.

Thorpe, H. (2017). Action sports, social media, and new technologies: Towards a research agenda. Communication \& Sport, 5, 554-578.

Thorpe, H., \& Dumont, G. (2018). The professionalization of action sports: Mapping trends and future directions. Sport in Society. Retrieved from https://doi.org/10.1080/17430437. 2018.1440715

Thorpe, H. \& Olive, R. (Eds.). (2016). Women in action sport cultures: Identity, politics and experience. London, England: Palgrave McMillan.

Thorpe, H., \& Wheaton, B. (2011a). "Generation X games", action sports and the Olympic movement: Understanding the cultural politics of incorporation. Sociology, 45, 830-847.

Thorpe, H., \& Wheaton, B. (2011b). The Olympic movement, action sports, and the search for Generation Y. In J. Sugden \& A. Tomlinson (Eds.), Watching the Olympics: Politics, power and representation (pp. 182-200). London, England: Routledge.

Thorpe, H., \& Wheaton, B. (2013). Dissecting action sports studies: Past, present, and beyond. In D. Andrews \& B. Carrington (Eds.), A companion to sport (pp. 341-358). Chichester, England: Wiley Blackwell.

Thorpe, H., \& Wheaton, B. (2017). The X games: Re-imagining youth and sport. In L. Wenner \& A. Billings (Eds.), Sport, media and mega-events (pp. 247-261). Abingdon, England: Taylor \& Francis.

Wheaton, B., \& Thorpe $\square$ press). Action sports, the Olympic Games, and the opportunities and challenges onder equity: The cases of surfing and skateboarding. Journal of Sport and Social Issues.

Walker, H., Soroka, M., \& Kellett, P. (2005, September 22-23). The profit-driven action sport industry working within the not-for-profit Australian sport system: The case of freestyle BMX Australia and the Australian sports commission. Paper presented at the Australasian Nonprofit and Social Marketing Conference, Melbourne, Australia.

Wenner, L. (2010). Sport, communication and the culture of consumption: On evolving and emerging markets. American Behavioral Scientist, 53, 1451-1453. 
Wenner, L. \& Billings, A. (Eds.). (2017). Sport, media and mega-events. Abingdon, England: Taylor \& Francis.

Wensing, E., \& Bruce, T. (2003). Bending the rules: Media representations of gender during an international sporting event. International Review for the Sociology of Sport, 38, 387-396. Retrieved from https://doi.org/10.1177/1012690203384001

Wheaton, B. (2005). Selling out? The globalization and commercialization of lifestyle sports. In L. Allison (Ed.), The global politics of sport (pp. 140-161). London, England: Routledge.

Wheaton, B. (2007). After sport culture: Rethinking sport and post-subcultural theory. Journal of Sport and Social Issues, 31, 283-307. Retrieved from https://doi.org/10. $1177 / 0193723507301049$

Wheaton, B. (Ed.). (2012). The consumption and representation of lifestyle sports. London, England: Routledge.

Wheaton, B. (2013). The cultural politics of lifestyle sport. London, England: Routledge.

Wheaton, B. (2017). Surfing through the life-course: Silver surfers' negotiation of ageing. Annals of Leisure Research, 20, 96-116. Retrieved from https://doi.org/10.1080/ 11745398.2016.1167610

Wheaton, B., \& Beal, B. (2003). "Keeping it real": Subcultural media and the discourses of authenticity in alternative sport. International Review for the Sociology of Sport, 38, $155-176$.

Wheaton, B., \& Thorpe, H. (2016). Youth perceptions of the Olympic Games: Attitudes towards action sports at YOG and Olympic Games. IOC report. Retrieved from https:// library.olympic.org/Default/doc/SYRACUSE/165853/youth-perceptions-of-the-olympicgames-attitudes-towards-action-sports-at-the-yog-and-olympic-games-?_lg=en-GB 